\title{
Optimization of Location-Routing for the Waste Household Appliances Recycling Logistics under the Uncertain Condition
}

\author{
Luojun YANG, Junhua GUO*, Cheng ZHANG, Ping WAN, Hao LI
}

\begin{abstract}
Waste household appliances and electronic products usually contain harmful substances which need scientific and reasonable collection, classification, processing, recovery and disposal to achieve sustainable and effective recycling and utilization. In recent years, due to the poor management of waste household appliances recycling logistics system, safety accidents occur frequently, which seriously harm the health and life safety of the society. This paper studies the risk management of recycling waste household appliances under uncertain conditions and establishes a risk measurement model under fuzzy population density. Considering the multi-stage and classification diversity of waste household appliances recycling logistics, the multi-objective location routing model and location - routing model are established respectively. Based on the model complexity analysis, the solution method of multi-objective model is designed. Finally, the validity of the model and algorithm is verified by examples and tests.
\end{abstract}

Keywords: closed loop supply chain; multi-objective optimization; recycling logistics; site selection-path; uncertainty condition; waste household appliances

\section{INTRODUCTION}

Waste household appliances recycling logistics based on closed-loop supply chain includes the transportation, collection, recovery and treatment of waste household appliances. The key to the design of logistics system is to determine the construction point of relevant logistics facilities and vehicle transportation route. Therefore, the core problem of the waste household appliances recycling logistics management system optimization based on the closed loop supply chain is: the key facility location [1] and transportation route optimization problem, namely location-routing combination optimization problem.

In general, the categories of waste household appliances are complex, and most of them contain toxic substances. If a safety accident occurs during the recycling process, the hazardous substances in waste household appliances can easily cause great harm to the surrounding environment, property and residents, among which, the harmful effects on the surrounding residents are the most direct and lasting. Therefore, the optimization goal of the waste household appliances recycling logistics management system should be balanced to avoid potential personnel harm to the greatest extent on the basis of taking into account the system cost minimization. It should be noted that the construction foundation of the waste household appliances recycling logistics management system is the urban logistics network. In the network, the population at each transport node and transport section is mobile, with typical characteristics of instability at the time level. Therefore, this chapter analyzes the hierarchical functions of the recycling logistics management system based on the structure of the closed-loop supply chain and the diversity of waste household appliances. Considering the uncertainty of population quantity in urban logistics network, the fuzzy population risk measurement model designed in Chapter 2.2 is adopted to establish the risk objective function. Focusing on the effective control of uncertain population risk in closed-loop supply chain management, considering the compatibility of different waste household appliances, classification technology and transport vehicles, the mathematical model with the minimum total cost and the minimum total risk is established to jointly optimize the two different decisions of facility location and vehicle route design for waste household appliances recycling logistics.

\section{LITERATURE REVIEW}

At present, there is little literature on designing and optimizing waste home appliances recycling logistics management system based on closed-loop supply chain from the perspective of risk control, which integrates the hazardous waste recycling management and waste home appliances recycling management together. Therefore, we will analyze research status at home and abroad only from three areas: hazardous waste location - routing problem, risk measurement and multi-objective optimization [2].

\subsection{Hazardous Waste Location-Routing Problem}

Since the 1990s, a number of researchers have studied the hazardous waste recycling logistics system, most of which are related to the coordination of facility location and transportation route optimization problem [3]. Zografos and Samara [4] were the first to propose hazardous waste location and routing model, in which they constructed three objectives including transport duration, transport and disposal risk. They ascertain the location of facilities and optimize the transportation route between generation nodes and facilities in the paper.

As interest orientation is taken into account, AydemirKaradag [5] put forward a mixed integer mathematical model for the hazardous waste location-routing problem. The objective function aims to maximize net present value of the entire HWM system. Profitability and environmental issues are provided simultaneously by applying the policies. A sensitivity study was conducted on different interest rates. The developed model provides efficient solutions for large-scale problems with a small relative MIP GAP and short CPU time.

Zhao and $\mathrm{Ke}$ [6] constructed a mathematical model to minimize costs and risks in consideration of the location, routing and inventory decision. They designed the 
algorithm based on TOPSIS method for the constructed multi-objective 0-1 mixed integer linear programming model, and the solution can reduce the risk and cost to the greatest extent. Rabbani et al. [7] considering the stochastic environment, studied the multi-period and multiple types of hazardous waste location-path problem, and established a stochastic mixed integer nonlinear programming model. In order to solve this problem, a Non-Dominated Sorting Genetic Algorithm-II (NSGA-II) combined with Monte Carlo simulation is adopted. The applicability of algorithms was tested on hypothetically generated problem instances. Araee et al. [8] considering the factors such as travel time, travel risks, and economic aspects, studied optimal transfer problem of hazardous waste. In addition, the focus is on the flexibility of transportation routes, and a multi-objective model is established. Finally, the multiobjective particle swarm optimization algorithm (MOPSO) and the non-dominated sorting genetic algorithm (NSGAII) are used to solve the model, and the performance of the meta-heuristic algorithm is compared. Rabbani et al. [9] studied the management of wastes produced in the automotive industry, proposing a capacitated location routing model with a heterogeneous fleet of vehicles. The model optimizes the route of collection vehicles, the location of collection centers, the inventory levels of these centers, the transportation classification of different types of waste, and the number of transportation vehicles. For solving this problem, a hybrid multi-criteria decisionmaking approach combining best worst method with PROMETHEE-II was proposed. Yilmaz et al. [10] studied the location-routing problem of hazardous waste management systems, established the reverse logistics network planning model with optimization objective of minimizing the environmental risk and the total system cost, which considered a new environmental impact definition, and the proposed model was applied to a case study in Turkey.

Asefi et al. [11] studied integrated solid waste management location-routing problem, and designed various types of municipal solid waste integrated management systems. They proposed a mixed integer linear programming (MILP) model to minimize the total cost of the ISWM system, including transportation costs and facility construction costs. A stepwise heuristic method is proposed in the framework of two meta-heuristic methods of variable neighborhood search (VNS) and hybrid VNS+simulated annealing algorithm. The results show that the solution solved by the proposed hybrid method can reduce cost to the greatest extent. Kargar et al. [12] established a location-path optimization model for hazardous medical waste including cost, treatment technology selection and the total medical waste stored, especially considering the diversity and compatibility of waste and treatment technology. A robust possibilistic programming approach is utilized to handle imprecise parameters in the model and a fuzzy goal programming method is employed to build up a multi-objective model.

Through the analysis of these literatures, it can be concluded that most of them aim to minimize the cost and risk, and some of them take equity of risk into account. The research content has gradually improved the detailed requirements of hazardous waste location-routing, focusing not only on cost saving, but also on risk reduction and even balanced distribution. Therefore, in this paper, according to the structural characteristics of waste home appliance recycling logistics management system, we will improve the system optimization content and method from the aspects of objective function of the model, solution methods and so on.

\subsection{Risk Measurement}

Since waste home appliances are generally the wastes containing harmful substances, scientific and effective risk management is needed in the process of recycling and treatment. Also the core of risk management is to measure the risk of harmful substances.

Specifically, since most waste home appliances are dangerous, if the recycling is not properly handled, it will not only damage the environment, but also pose a threat to people's health. Therefore, risk measurement should be taken as the key content of the optimization of waste home appliances recycling logistics management system. It should be noted that waste home appliances contain hazardous substances and belong to a specific type of dangerous goods, and the risk measurement methods are mostly used for transport risk of dangerous goods analysis and measurement. Therefore, the research status of risk measurement in the field of dangerous goods transport is mainly discussed here [13].

Deng, F. et al. [14] studied the inventory risk management of hazardous waste production company, proposed a risk assessment system based on safety inventory of hazardous waste disposal, and build a hazardous waste inventory risk evaluation system based on the level of equipment, hazardous waste management, the characteristic of hazardous waste and operation. Then the BMW - TOPSIS mixed multi-criteria decision making method is used to solve the risk assessment of hazardous waste inventory problem. Wencheng, W. et al. [15] studied trace elements on soil pollution in improper e-waste recycling, through collecting typical e-waste recycling area soil samples, evaluated all kinds of heavy metals trace elements in soil impact on ecosystems and human health risk based on the index such as pollution, enrichment factor and potential ecological risk, hazard and damage indicators.

Huang, X. et al. [16] developed a RAAH conceptual model based on the scenario of dangerous goods transport accident, proposed the probability, strength and vulnerability of risk, and used ALOHA software to determine the scope of influence. This paper analyzes the vulnerability of regional units along the road, divides the vulnerability into exposure factor, sensitivity factor and adaptive capacity factor, and constructs the vulnerability index system. On this basis, the risk function and its constituent elements are established, and the risk quantification of unit area along the road is realized. Liu, S. et al. [17] proposed a risk measurement model based on spectral function, and reflected the decision maker's preference by accurately defining the spectral function. The only dangerous goods transportation path based on expected risk, maximized risk and conditional risk could be determined by using spectral risk measurement.

Kazancoglu, Y. et al. [18] studied the risk assessment problem of e-waste recovery, adopted SRA as the risk 
classification tool for e-waste recovery, and established a sustainable risk assessment system for e-waste recovery under the conditions of risks and uncertainties. Ginger, Y. et al. [19] proposed a minimization maximum path risk population exposure model based on travel time and fuzzy accident rate. Pirmin Fontaine et al. [20], in consideration of the public's fear of dangerous goods transportation and the government's demand for fair distribution of risks, proposed a population risk of multiple modes of transportation based on risk redistribution, realizing a more equitable and reasonable risk layout under the condition of keeping the total risk unchanged. Zhao, J. et al. [21] designed risk diffusion models under different water environments and proposed a pipeline environmental risk assessment method based on measuring environmental risk by pipeline leakage volume.

Studies show that in the process of transportation, the leakage of harmful substances caused by accidents will cause a certain degree of harm to the surrounding residents, property and environment $[22,23]$ compared with previous researchers, who prefer to take social risks, such as population and property risks into account. In the present, more environmental risk models have been established to analyze and measure risks. Existing studies have considered the probability of the occurrence of risks and the consequences caused by risks, but it can be seen that most of the studies have not considered the uncertainty of risks; there are few researches on the uncertainty of population density. In order to improve the existing research, this paper intends to consider the uncertainty of population density and research in terms of cost, equity of location risk and equity of transportation risk [24].

\subsection{Multi-Objective Solution Method}

For the existing model of hazardous waste locationrouting problem, multi-objective and multi-constraint models are usually to be seen and "model transformation + software direct calculation/accurate algorithm calculation" is a common mode of solving multi-objective model. With the deepening of the complexity of the problem and the expansion of the research scale, in order to ensure the performance of the solution, scholars have introduced heuristic algorithm to the location-routing problem. Existing researches mainly focus on using improved intelligent algorithms or exploring new hybrid intelligent algorithms to solve specific models built for specific application scenarios. To this end, this paper takes the multi-objective optimization method in the field of hazardous waste recycling management as an example to summarize the research status.

Ahani, M. et al. [25] proposed a multi-stage solution to solve sustainable biomass supply chain network design problem. This method uses the geographic information system to obtain the candidate location of the facility, and uses the analytic hierarchy process to improve the location. Finally, it uses the augmented constraint method to solve the multi-objective MILP model. Rabbani et al. [26] studied a hazardous waste location-routing problem, simultaneously minimizing three significant criteria, including total cost, total transportation risk of hazardous waste related to population exposure, and site risk. They designed Nondominated Sorting Genetic Algorithm II
(NSGA-II) and Multi-Objective Particle Swarm Optimization algorithms to solve industrial hazardous waste location-routing problem focusing on vehicle routing decisions [27]. The results obtained from experiments confirm the superiority of NSGA-II over MOPSO. Wichapa and Khokhajaikiat [28] focused on the location routing problem for medical infectious waste disposal. They built multi-objective model, and developed a hybrid approach consisting of the fuzzy AHP, Goal Programming (GP), and Genetic Algorithm (GA) method. Zhao, J. et al. [29] studied the city garbage disposal facilities allocation problem, used fuzzy expert system to determine environmental cost assessment criterion of the solid waste management system, evaluated the economic and environmental costs of each facility, built a multiobjective model about the optimal configuration in the urban garbage disposal capacity, which was aiming at minimizing economic and environmental cost, and the non-dominated sorting genetic algorithm II (NSGA II) was used to solve the multi-objective model.

Homayouni and Pishvaee [30] designed a collection and disposal network of hazardous hospital waste under uncertain condition. They built a multi-objective robust optimization model. The objectives are to concurrently minimize the total cost, and the total risk of transportation and operations. The augmented $\varepsilon$-constraint method was employed for solving these problems. Durmaz et al. [31] studied sustainable biomass supply chain network design problem and proposed multi-objective mixed integer linear programming model. The model incorporates the two objective functions of maximization of the profit, and minimization of total distance between poultry farms and biogas facilities. Based on the augmented $\varepsilon$-constraint method, they designed a novel multi-stage solution methodology. Nagy and Salhi $[32,33]$ took the problem of transportation route arrangement as a sub-problem to deal with the larger location problem. For the location-routing problem, they proposed a heuristic method based on nested methods, in which a simple tabu search version was embedded to improve the solution. Sergio et al. [34] studied the location-routing problem with vehicle capacity limit which aims at minimizing location and routing cost. They also proposed a sequential heuristic algorithm based on clustering analysis to solve the model. In addition, four grouping techniques and six adjacency degrees are used to obtain several versions of the heuristic algorithm.

The above research shows that the heuristic algorithm not only guarantees the performance, but also facilitates the sensitivity analysis when solving large-scale problems. However, we should pay attention to the diversity and contradiction in the combinatorial optimization process of hazardous waste location-routing. Therefore, in the application of uncertainty theory, how to solve the contradiction between multiple objectives is the main content of this paper.

\subsection{Existing Research Problems}

Although current research scholars have obtained a lot of research results in related management fields, from the perspective of closed-loop supply chain management [35], the design and optimization of waste household appliances recycling logistics management systems show that the 
application of the above research results still has the following deficiencies:

(1) Very few researches design specific waste household appliances recycling logistics management system according to the different geographical scope.

Most of the logistics management systems designed by the existing research results are from the perspective of enterprise management and only design the logistics structure in the direction of reverse logistics. However, there are differences in the geographical scope of waste household appliances logistics network, as well as in the logistics direction of two-way compound type and one-way unified type. Therefore, it is necessary to fully combine the closed-loop supply chain integrated logistics system and design a separate logistics management system according to the different service geographical scope of waste home appliance recycling management.

(2) Risk control and equity are rarely considered in modeling.

Most of the existing research on the optimization of the recycling and logistics management system of waste household appliances are aimed at minimizing costs. Risk factors are rarely introduced in the recycling management of waste home appliances, and risk fairness is rarely considered in the hazardous waste logistics, which fails to present realistic requirements objectively, and especially the residents around the logistics facilities have stronger demands for risk fairness. And the model will be more reasonable after adding more risk fairness.

(3) Risk measurement lacks discussion under uncertain conditions.

Previous studies on risk measurement are mainly on the basis of determination of fixed parameters estimation, but in the actual transportation risks are in the process of multiple factors, such as the probability of danger happening, transportation time, the kinds of transportation of hazardous waste, transport waste production and so on [36].

These are all uncertain, and only a few of them can take into account the fuzzy nature of population and build a risk measurement model on this basis.

(4) The universality of the solution method under uncertain conditions needs further study.

The existing location-routing model mainly considers the research under the deterministic environment, which has certain limitations. And in the network design, the conditions of uncertainty are introduced into the traditional location-routing model. But whether the solution algorithm of the original deterministic model is still applicable, this requires further in-depth research.

\section{PROBLEM DESCRIPTION}

\subsection{Multi-Category Waste Household Appliances Logistics Management System}

In actual management, in order to distinguish between different types of properties and the degree of the scrap of waste household appliances, to confirm the number can be recycled as soon as possible, to reduce the potential hazard of waste household appliances, most of the waste household appliances will be collected as a whole first, and then entered into the recycling or ultimate scrap disposal process after reasonable classification by the collection center [6]. On the one hand, the collection center has the functions of centralization, temporary storage and classification of waste household appliances [37]. On the other hand, the collection center is specially equipped with a batch of special vehicles for handling the collection of waste household appliances from urban residential areas and the centralized transport business in the later period. Therefore, the chapter draws lessons from the business process of management practice, and constructs a multilayer network of waste household appliance logistics management system including collection, recycling and treatment (Fig. 1). The generation node of waste household appliances is located at the node of the first floor of the network, and the collection center is at the second floor. The third floor is the recycling center and processing center. A large number of waste household appliances of different types flow between the nodes of each floor by means of vehicle transportation. The collection center is equipped with a certain number of vehicles, which are responsible for transporting electrical appliances waste from the production point to the collection center. After the sorting of different technologies in the collection center, household appliances waste that can be recycled will be transferred to the recycling center, while the waste that cannot be recycled will be directly transferred to the treatment center.

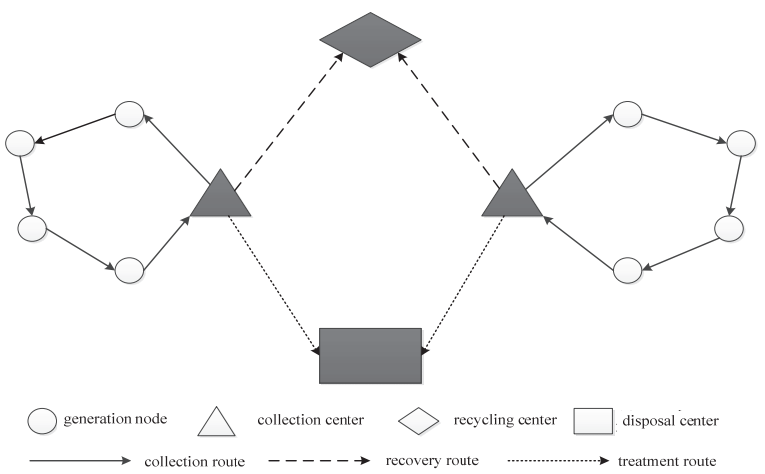

Figure 1 Multi-category waste appliance recycling logistics management system based on closed-loop supply chain (Note: The shaded is the selected location)

It should be noted that first, in the logistics management system, the collection route is circular, that is, the vehicle starts from the collection center to collect and transport waste household appliances, and then returns to the same collection center. The recycling route and treatment route are chains which transfer electrical appliances waste from the collection center to the recycling center or treatment center. Therefore, how to optimize two different types of vehicle transportation routes at the same time is the focus of this chapter. Secondly, this chapter takes logistics facilities and transportation routes as risk sources, as well as adopts the fuzzy population casualty risk measurement model, through considering the compatibility of Waste Household Appliances Classification of the compatibility of Technology and Waste Household Appliances - Transport Vehicle, and designs the location-routing model with the minimum total cost and the minimum total risk.

\subsection{Problem Analysis}

In the waste household appliance recycling logistics management system, many collection centers are often 
built, assuming that each collection center has the same capacity. According to the characteristics of the logistics management system, and according to the different starting and ending points of each vehicle, the collection route, recovery route and treatment route can be classified into two categories: tour route and chain route, and they can be defined as follows:

Definition of one tour of transportation route: the vehicle starts from any collection center with no load and goes through several generation nodes in turn, and then returns to the same collection center with full load. The vehicle's running route is a tour, that is, the collection route is a tour route.

Definition of two chain transportation route: When a fully loaded vehicle transports waste household appliances from any collection center to any recycling center or any processing center, the running route of the vehicle is a chain, that is, the recycling route and the processing route are independent chain routes.

According to the designed waste household appliance recycling logistics management system, based on the diversity of waste household appliances, this chapter designs constraints about the compatibility of Waste Household Appliances-Classification Technology and the compatibility of Waste Household Appliances-Transport Vehicles. Based on closed-loop supply chain management, this chapter sets logistics facility capacity restriction, vehicle capacity restriction, and network flow conservation restriction. Based on the balance consideration of cost and risk factors, this chapter constructs objective functions to minimize the total cost and minimize the risk of fuzzy population casualties, and reflects the idea of equilibrium avoidance in the risk objective function. This chapter sets the optimization content of the location-routing problem in the following way:

(1) Determine the location of the collection center and the type of processing technology introduced;

(2) Determine the location of the recovery center and treatment center;

(3) Design a tour route for collecting vehicles;

(4) Design a chain route for the operation of transfer vehicles;

(5) Set the total number of collection vehicles configured in the collection center.

\subsection{Uncertain Programming Theory}

There are many uncertain factors in the waste household appliances recycling logistics management system, such as the uncertainty of collection time, the uncertainty of production location, the uncertainty of quantity, the uncertainty of collection quantity and quality, etc., which need to rely on probabilistic fuzzy set theory to be solved.

\subsubsection{Definition of Membership}

In order to explore the solution in uncertain environment, Zadeh et al. put forward the concept of fuzzy set: Here is a fuzzy set $\tilde{A}$ on the domain $X$, which means for any $x \in \tilde{A}$, and there is a number $\mu_{\sim}(x) \in[0,1]$ that corresponds to it. $\mu_{\sim}(x)$ is called the degree of membership $A$

of x to $\tilde{A} \cdot \mu_{\tilde{A}}$ is called the membership function of $\tilde{A}$.

\subsubsection{Triangular Fuzzy Variable}

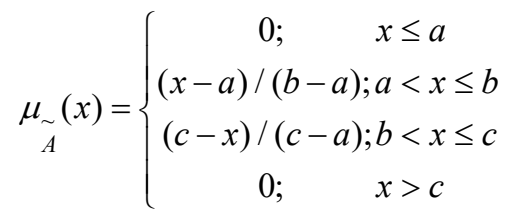

In this chapter, the triangular fuzzy number $\tilde{A}=(a, b, c)$ is used to represent the uncertainty of floating population density, and its membership function is shown in Eq. (1). At that time, the triangle fuzzy number is the most likely value, $\mu_{\sim}(x)=1$. When $x \leq a$ or $x \geq c$, the triangular fuzzy number takes the most impossible value, $\mu_{\sim}(x)=0$.

A

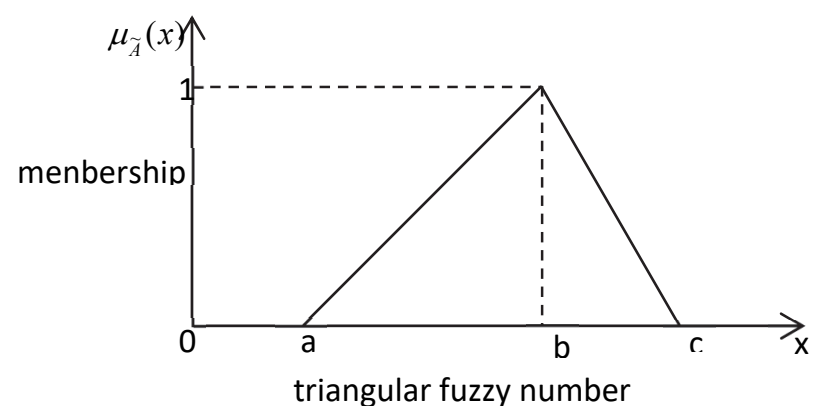

Figure 2 Membership function of triangular fuzzy Numbers

Das, S. K. et al. set the value range of fuzzy parameters based on avoiding the fuzziness of model parameter values. However, in practical practice, the value range of parameters within a certain range is proved to be a probability distribution. It can be seen from Fig. 2 that this feature is very consistent with the membership function of triangular fuzzy Numbers.

\subsection{Model Formulation}

In this chapter, we construct an urban logistics network based on the waste home appliances recycling logistics management system designed before. Under the premise of the minimum cost and balanced fuzzy risk defined by casualties, the problem of facility location and vehicle routing design is synergistically optimized.

\subsubsection{Basic Assumption}

(1) There is no capacity limit on each section of the urban logistics network;

(2) Hazardous impact area at key nodes and on key transport links is defined by a risk zone with a fixed damage radius and the floating population within the risk zone is calculated into the overall risk; 
(3) Different categories of waste home appliances which are incompatible are forbidden to be transported by the same vehicle at the same time;

(4) Each kind of waste home appliances can be disposed by matched classification technique;

(5) The volume of each waste home appliance transported and disposed in each facility is considered as potential risk source.

\subsubsection{Parameter Declaration}

(1) Set

Let $N(V, E)$ be a road network with the set of vertices $V(1,2, \ldots, v)$ and the set of edges $E(1,2, \ldots, e)$, where $V=G \cup U \cup R \cup D$.

$G(1,2, \ldots, g)$ waste home appliances generation nodes.

$U(1,2, \ldots, u)$ collection centers.

$R(1,2, \ldots, r)$ recycling centers.

$D(1,2, \ldots, d)$ disposal centers.

$W(1,2, \ldots, w)$ types of waste home appliances.

$K(1,2, \ldots, k)$ type of classification technique.

$L(1,2, \ldots, l)$ type of vehicles on tour.

(2) Parameters

$T C_{w}$ store unit cost of transporting waste home appliances $w \in W$ per kilometre in the collecting trip.

$T C_{w}{ }^{\text {treat }}$ unit cost of transporting waste home appliances $w \in W$ per kilometre in the transfer trip.

$U F C_{i k}$ fixed cost of bringing classification technique $k \in K$ to the collection center $i \in U$.

$R F C_{i}$ and $D F C_{i}$ represents the fixed cost of building the recycling center $i \in R$ and the disposal center $i \in D$, respectively.

$g_{w i}$ amount of waste home appliances $w \in W$ generated at node $i \in G$

$\phi_{w k}$ recyclable percentage of waste home appliances $w \in W$ screened by classification technology $k \in K$.

$h_{i j}$ length of edge $(i, j) \in E$.

$p_{i}{ }^{\text {node }}$ rate of accident happened at node $i \in V$.

$p_{i j}^{\text {edge }}$ rate of accident happened at edge $(i, j) \in E$

$R_{i w}{ }^{\text {node }}$ damage radius of waste home appliances $w \in W$ accidents happened at node $i \in V$

$R_{i j w}{ }^{\text {edge }}$ damage radius of waste home appliances $w \in W$ accidents happened at edge $(i, j) \in E$

$p \widetilde{o} p_{i}^{\text {node }}$ Quasi-triangular fuzzy numbers, represents the population density at node $i \in V$, po $p_{i}{ }^{\text {node }} \approx\left(\right.$ pop $_{i}{ }^{d}$, pop $_{i}{ }^{m}$, pop $\left._{i}{ }^{u}\right), 0 \leq$ pop $_{i}{ }^{d} \leq$ pop $_{i}{ }^{m} \leq$ pop $_{i}{ }^{u}$, ofwhich, $" \approx$ " represents the value range of $p \tilde{o} p_{i}^{\text {node }}$ is $\left[\right.$ pop $_{i}{ }^{d}$, pop $\left._{i}{ }^{u}\right]$, and most likely to be pop $_{i}{ }^{m}$.

Similarly, Quasi-triangular fuzzy numbers $p \tilde{o} p_{i j}{ }^{\text {edge }}$ represents the floating population density on edge $(i, j) \in E$. $\delta_{i w}{ }^{\text {node }}$ fatality rate of waste home appliances $w \in W$ accidents happened at node $i \in V$

$\delta_{i j w}{ }^{\text {edge }}$ fatality rate of waste home appliances $w \in W$ accidents happened on edge $(i, j) \in E$

$U K C_{i k}$ and $U K M_{i k}$ represents the capacity and minimum throughput requirement of technique $k \in K$ in collection centers $i \in U$, respectively

$R C_{i}$ and $D C_{i}$ represents the capacity of recycling centers and disposal centers, respectively

$V C A P$ vehicle capacity

$C O M_{w k}$ is $0-1$ constants, 1 if the waste home appliances $w \in W$ and technique $k \in K$ matching, 0 otherwise.

$C O N_{w l}$ is $0-1$ constants, 1 if the waste home appliances $w \in W$ and vehicle $l \in L$ matching, 0 otherwise

$M$ the infinite positive integer, when $|G \cup U|$ is the number of nodes in the set union of $G \cup U$, exist

$M \geq|G \cup U|$

\subsubsection{Fuzzy Multi-Objective Location-Routing Model}

$$
\begin{aligned}
\min f_{1} & =\sum_{i \in U} \sum_{k \in K} U F C_{i k} o_{i k}+\sum_{i \in R} R F C_{i} p_{i}+ \\
& +\sum_{i \in D} D F C_{i} q_{i}+\sum_{w \in W} \sum_{j \in G \cup U} \sum_{l \in L} T C_{w}^{\text {store }} h_{i j} x_{w i j l}+ \\
& +\sum_{w \in W} \sum_{i \in U} \sum_{j \in R} T C_{w}^{\text {treat }} h_{i j} y_{w i j}+ \\
+ & \sum_{w \in W} \sum_{i \in U} \sum_{j \in D} T C_{w}^{\text {treat }} h_{i j} z_{w i j} \\
\min f_{2}= & \left(\sum_{w \in W} \sum_{i \in U} p_{i}^{\text {node }} \times \pi \times R_{i w}{ }^{\text {node2 }} \times p \tilde{o} p_{i}^{\text {node }} \times \delta_{i w}{ }^{\text {node }} \times \sum_{k \in K} u_{w i k}\right. \\
& +\sum_{w \in W} \sum_{i \in R} p_{i}^{\text {node }} \times \pi \times R_{i w}{ }^{\text {node2 } 2} \times p \tilde{o} p_{i}^{\text {node }} \times \delta_{i w}{ }^{\text {node }} \times r_{w i} \\
& \left.+\sum_{w \in W} \sum_{i \in D} p_{i}^{\text {node }} \times \pi \times R_{i w}{ }^{\text {node2 } 2} \times p \tilde{o} p_{i}^{\text {node }} \times \delta_{i w}{ }^{\text {node }} \times d_{w i}\right) / v
\end{aligned}
$$

$\min f_{3}=\left(\begin{array}{l}\sum_{w \in W} \sum_{(i, j \in E)} p_{i j}^{\text {edge }} \times 2 \times R_{i j w}^{\text {edge }} \times h_{i j} \times p \tilde{o} p_{i j}^{\text {edge }} \\ \times \delta_{i j w}^{\text {edge }} \times\left(\sum_{l \in L} x_{w i j l}+a_{w i j}+b_{w i j}\right)\end{array}\right) / e$

s.t.

$\sum_{j \in G \cup U} \sum_{l \in L} x_{w j i l}=1, \forall i \in G, \forall w \in W$

$\sum_{j \in G \cup U} x_{w j i l}-\sum_{j \in G \cup U} x_{w i j l}=0$,

$\forall w \in W, \forall i \in G \cup U, \forall l \in L$

$\sum_{w \in W} \sum_{i \in U} \sum_{j \in G} x_{w j i l} \leq 1, \forall l \in L$

$c_{w i l}-c_{w j l}+M x_{w i j l} \leq M-1$,

$\forall w \in W, \forall i, j \in G, \forall l \in L$ 
$x_{w i h l}+x_{w h i l}-v_{w i j} \leq 1, \forall w \in W, \forall h \in G$,

$\forall i \in U, \forall j \in U, \forall l \in L$

$\sum u=\sum v g, \forall w \in W, \forall i \in U$

$\sum_{k \in K} \phi_{w k} u_{w i k}=\sum_{j \in R} y_{w i j}, \forall w \in W, \forall i \in U$

$\sum_{k \in K}\left(1-\phi_{w k}\right) u_{w i k}=\sum_{j \in D} z_{w i j}, \forall w \in W, \forall i \in U$

$r_{w i}=\sum_{j \in U} y_{w j i}, \forall w \in W, \forall i \in R$

$d_{w i}=\sum_{j \in U} z_{w j i}, \forall w \in W, \forall i \in D$

$\sum_{w \in W} u_{w i k}=o_{i k} U K C_{i k}, \forall i \in U, \forall k \in K$

$\sum_{w \in W} r_{w i}=p_{i} R C_{i}, \forall i \in R$

$\sum_{w \in W} d_{w i}=q_{i} D C_{i}, \forall i \in D$

$\sum_{w \in W} u_{w i k} \geq o_{i k} U K M_{i k}, \forall i \in U, \forall k \in K$

$y_{w j i} \leq a_{w i j} M, \forall w \in W, \forall i \in U, \forall j \in R$

$z_{w j i} \leq b_{w i j} M, \forall w \in W, \forall i \in U, \forall j \in D$

$u_{w i k} \leq U K C_{i k} C O M_{W k}, \forall i \in U, \forall k \in K, \forall w \in W$

$\sum_{i \in G \cup U} \sum_{j \in G} x_{w i j l} \times g_{w j} \leq V C A P C O N_{w l}, \forall w \in W, \forall l \in L$

$o_{i k}=0,1, \forall i \in U, \forall k \in K$

$p_{i}=0,1, \forall i \in R$

$q_{i}=0,1, \forall i \in D$

$v_{w i j}=0,1, \forall w \in W, \forall i \in G, \forall j \in U$

$x_{w i j l}=0,1, \forall w \in W, \forall(i, j) \in G \cup U, \forall l \in L$

$a_{w i j}=0,1, \forall w \in W, \forall i \in U, \forall j \in R$

$b_{w i j}=0,1, \forall w \in W, \forall i \in U, \forall j \in D$

$y_{w i j} \geq 0, \forall w \in W, \forall i \in U, \forall j \in R$

$z_{w i j}=0,1, \forall w \in W, \forall i \in U, \forall j \in D$ $u_{\text {wik }} \geq 0, \forall w \in W, \forall i \in U, \forall k \in K$

$r_{w i} \geq 0, \forall w \in W, \forall i \in R$

$d_{w i} \geq 0, \forall w \in W, \forall i \in D$

$c_{w i l} \in Z, \forall w \in W, \forall i \in G, \forall l \in L$

Eqs. (3) to (5) are the objectives. Eq. (3) minimizes the sum of the fixed costs, collection costs and transfer costs of each center, and Eq. (4) with the idea of spreading the risk fairly, is the minimization of total location risk after equilibrium, which is the minimum population exposure tons in each center. Similarly, Eq. (5) is the minimization of total transport risk after equilibrium, which reports the total number of casualties exposed to the waste home appliances transportation in tours.

Constraints are given by Eq. (2) and Eqs. (2) to (36). Eq. (6) ensures that any category of waste home appliances generated at each generation node is transported by the only collection vehicle of the only center; Eq. (7) ensures connectivity between any two points on the tour; Eq. (8) ensures transport vehicles on any tour are equipped by the only collection center. Eqs. (9) and (10) prevent subtours. The flow equation constraints for the waste home appliances between each center and edge are given by Eqs. (11) to (12). The centers capacity constraints are shown at Eqs. (13) to (18). Eq. (19) presents minimum throughput requirement for the collection center. Eqs. (20) and (21) are the logical constraints of the variable. Eqs. (22) and (23) represent the compatibility constraint of "waste home appliances-technique" and "waste home appliancesvehicle". Lastly, the decision variable domains can be found at Eqs. (24) to (36).

\subsubsection{Feature Analysis}

In this chapter, we constructed a fuzzy multi-objective 0-1 mixed integer linear programming model. The model contains 0-1 decision variables, integer decision variables and continuous decision variables. Six constraint groups are set, which include tour transport constraint, flow conservation constraint, capacity constraint, logic constraint, compatibility constraint and domain constraint of decision variables. Meanwhile, we designed three objective functions including the minimum total cost, the minimum total balanced risk of location and transportation. Besides, dimensions of risk and cost and dimensions of the location and transportation risk are different (dimension of cost is currency, dimension of location risk is population tons, dimension of transport risk is population).

If there are $v$ nodes, $e$ arcs, $g$ production points, $u$ collection centers, $r$ recycling centers, $d$ disposal centers, $w$ category of waste home appliances, $k$ technologies and $l$ transportation vehicles in the waste home appliances transport network, the mathematical model contains $u k+$ $r+d+w g u+w g l+w u l+w u \mathrm{r}+w u d 0-1$ variables, wur + $w u d+w u \mathrm{k}+w r+w d$ continuous variables and $w g l$ integer decision variables. Meanwhile, under this background, there are $(u 2 w g l+g 2 w l+w u r+w u d+w u k+w u l+w g l+$ $3 w u+2 u k+w g+w r+w d+w l+r+d+1)$ linear 
constraints. Considering the complexity of the model, it is difficult to solve the new location-routing model directly with conventional mathematical optimization software. For this situation, a new solution needs to be designed aiming at the complex features of the model, which will be introduced in detail in the next chapter.

In this chapter, based on the closed loop supply chain, we designed the recycling logistics management system of multi-category waste home appliances. According to the characteristics of the system, the optimization background of logistics management system was set as follows: unstable population, which meant the risk of closed-loop supply chain management was uncertain. At the same time, the core optimization contents were defined as follows: facility location and vehicle routing optimization problems. According to the applicability of combinatorial optimization problem, we analyzed the specific optimization content of the problem. Combined with the structure of urban logistics network, under the background of uncertain population density, three kinds of decision variables, three objective functions and six kinds of constraints were designed, and the location-routing model of 0-1 mixed integer linear programming with fuzzy multiobjective was constructed. We also analyzed the complexity characteristics of the model.

\section{THE METHOD OF SOLUTION}

Under the premise of uncertain risk of closed-loop supply chain management, a fuzzy multi-objective 0-1 hybrid integer linear programming model is constructed in Chapter 3 in order to co-optimize the location and routing problem of multi-category waste household appliances recycling logistics. In general, unlike the solution of singleobjective model with global optimality, the solution of multi-objective model often results in a Pareto solution set, which is difficult to find an effective method to compare and analyse the quality of each solution. In this regard, this chapter will design effective solution ideas for the complexity of the model, setting up the solution steps of the model according to the method of dimensionless technology and multi-objective transformation, and verifying the validity of the model and the solution method through multiple designed examples and tests.

The methods of solving multi-objective models are constraint method, stratified sequencing method, efficacy coefficient method, evaluation function method, etc. Among them, objective programming and linear weighting are commonly used as effective solution methods. In this regard, this paper will transform the multi-objective model into a new single-objective model by using weighted target programming method, and use conventional business optimization software to calculate directly. In the process of calculation, different sub-objective weight coefficient allocation schemes will be fully considered to provide a variety of effective solutions for decision makers with different preferences.

\subsection{Multi-Objective Conversion}

Using weight target programming method to turn a multi-objective model into a new single-objective model is as follows: $\min z=\sum \frac{\lambda \times n}{\varepsilon}$

S.t. (2), (6) to (36) and

$z_{1}-n_{1}^{+}=z_{1}^{*}$

$z_{2}-n_{2}^{+}=z_{2}^{*}$

$z_{3}-n_{3}^{+}=z_{3}^{*}$

where, $z_{1}, z_{2}$, and $z_{3}$ are the corresponding sub-objective functions in the model $Z(A) . \lambda_{1}, \lambda_{2}$ and $\lambda_{3}$ are weight coefficients of each sub-objective, and $\lambda_{i} \in[0,1]$ and $\sum_{i=1}^{3} \lambda_{i}=1$. In addition, $\varepsilon_{i}$ is percentage dimensionless coefficient of each sub-objective. $n_{i}^{+}$is positive deviation variable of each sub-objective. $Z_{i}^{*}(i=1,2,3)$ is the optimal value for the sub-objective.

The Eq. (37) is an expression of the single-objective model after the objective programming conversion. The Eqs. (38) to (40) are general constraints of the objective programming method, indicating that the optimal value of the sub-objective determines the value of the positive deviation variable $n_{i}^{+}(i=1,2,3)$. Obviously, when the optimal values for each sub- objective are determined, the model $Z(B)$ can be solved directly through the software.

\subsection{Defuzzification}

Usually, the converted single-objective optimization model can be solved directly by conventional mathematical optimization software, but this paper builds a fuzzy mathematical model, which needs to be pre-processed before putting parameters into solving. Among them, the population density in the network is a triangular fuzzy number, $\quad$ oo $p_{i}{ }^{\text {node }} \approx\left(\right.$ pop $_{i}{ }^{d}$, pop $_{i}{ }^{m}$, pop $\left._{i}{ }^{u}\right)$, which can be obtained from $\quad p \tilde{o} p_{i}{ }^{\text {node }}=\frac{2 p o p_{i}{ }^{m}+p o p_{i}{ }^{d}+p o p_{i}{ }^{u}}{4} \quad$ by defuzzification [38].

Its specific implementation case is as follows:

Assume $p \tilde{o} p_{i}^{\text {node }} \approx(60,80,90)$ representing the number of triangular blurs of the population density (person/square kilometer) at the node $i$ in a day. After the defuzzification, it is $p \tilde{o} p_{i}^{\text {node }}=\frac{2 \times 80+60+90}{4}=77.5 \approx 80$ (person/square kilometer). This method is suitable to calculate all population density in the network.

\subsection{The Solution Steps}

After transforming the fuzzy multi-objective location and routing model into a single-objective optimization model, the solution steps are designed as follows:

Step 1: Define sets and parameters and input relevant data; 
Step 2: Use Java to call the Cplex optimization software to solve the optimization problem when the subobjective is minimized and get the best value $z_{i}{ }^{*}, i=1,2,3$.

Step 3: Construct a positive deviation variable $n_{i}^{+}$and establish constraints based on the optimal value of the subobjective: $z_{i}-n_{i}^{+}=z_{i}^{*}, i=1,2,3$.

Step 4: Use the percentage dimensionless technology to determine the percentage dimensionless coefficient $\varepsilon_{i}=\frac{z_{i}^{*}}{100}, i=1,2,3$.

Step 5: Select the weight coefficient for the subobjective $\lambda_{i}, i=1,2,3$.

Step 6: Use to call the Cplex optimization software to directly solve the transformed single-objective model $Z(B)$.

Step 7: Output the location and routing optimization scheme.

\section{CALCULATION ANALYSIS}

According to the location-routing model (constructed in Chapter 3) of recycling uncertain multi-category waste household appliances based on the closed-loop supply chain, this paper first designs a basic calculation example to verify the effectiveness of the model and method; Then, the sensitivity analysis of different parameters in this basic example is carried out to test the robustness of the model and method.

\subsection{Basic Example}

This example sets up 15 production sites of waste household appliances (No. 1-15), and each 3 candidate nodes for collection center, recycling center, and processing center (No. 16-24). It should be noted that, under the basis of references [19, 39, 49-50], this article follows the setting of related parameters such as freight and construction cost, damage radius, and fatality rate; the other parameters are randomly generated by Matlab.

\section{(1) Basic information}

As shown in Fig. 3, simulate a city with a square area of about $50 \times 50$ square kilometers.

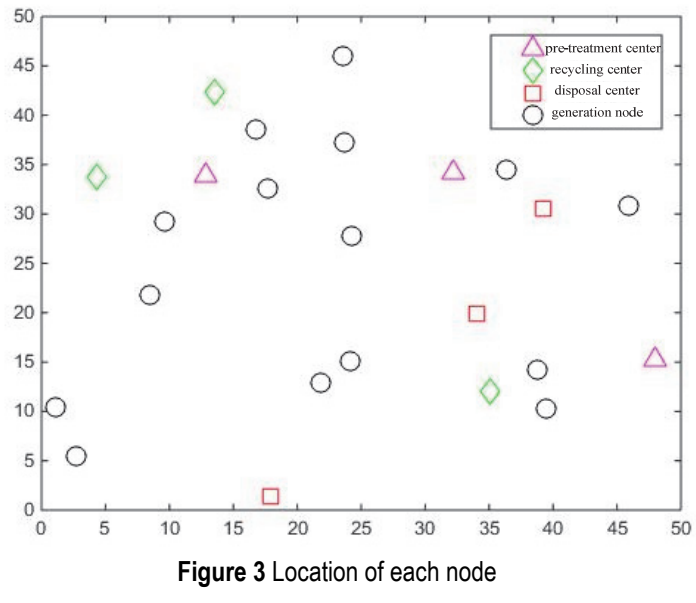

Each node in the area is randomly generated by Matlab and the distance between the nodes is calculated according to the horizontal and vertical coordinates of the points. There are 3 types of waste household appliances at each production site (category 1-3), and their outputs are shown in Tab.1. The collection costs of each category are 250, 150 , and 330 yuan $/ \mathrm{km}$ respectively, and their corresponding transfer costs are 7.32, 3.66, and 8.12 yuan $/$ ton $\cdot \mathrm{km}$. The damage radius and fatality rate of various types of used appliances are shown in Tab. 2 .

Table 1 Weekly output of production sites

\begin{tabular}{|c|c|c|c|}
\hline $\begin{array}{c}\text { Production } \\
\text { site }\end{array}$ & $\begin{array}{c}\text { Type 1/ } \\
\text { tons/week }\end{array}$ & $\begin{array}{c}\text { Type 2/ } \\
\text { tons/week }\end{array}$ & $\begin{array}{c}\text { Type 3 / } \\
\text { tons/weeks }\end{array}$ \\
\hline 1 & 1 & 1 & 2 \\
\hline 2 & 2 & 1 & 3 \\
\hline
\end{tabular}

Table 2 Damage radius and fatality rate of appliances waste

\begin{tabular}{|c|c|c|c|}
\hline Parameter & Type 1 & Type 2 & Type 3 \\
\hline Damage radius / $\mathrm{km}$ & 1.6 & 0.8 & 8 \\
\hline Fatality rate & $29.20 \%$ & $1.90 \%$ & $58.93 \%$ \\
\hline
\end{tabular}

The relevant information of each collection center is shown in Tab. 3. Each collection center can set 3 types of classification technologies (techniques 1-3). The compatibility between waste household appliances and technologies is shown in Tab. 4. Three types of vehicles can be used for transportation in collection center (vehicles 1-3), the maximum load capacity of all vehicles is 25 tons, the compatibility between the waste and vehicles is shown in Tab. 5; the relevant information of each recycling center and processing center is shown in Tab. 6 and Tab. 7.

The accident probability and population density of each node and arc are randomly generated by Matlab. The fuzzy population density of three points is randomly taken in the three intervals of $[20,40],[40,80]$, and $[80,100]$, then perform defuzzification from which the converted fixed values are used for programming calculation.

\begin{tabular}{|c|c|c|c|c|c|c|c|c|c|}
\hline \multirow{2}{*}{ 莺 } & \multicolumn{3}{|c|}{$\begin{array}{l}\text { Fixed construction } \\
\text { cost / 106yuan/year }\end{array}$} & \multicolumn{3}{|c|}{$\begin{array}{l}\text { Minimum } \\
\text { processing capacity } \\
\text { / tons/week }\end{array}$} & \multicolumn{3}{|c|}{$\begin{array}{c}\text { Maximum } \\
\text { processing capacity } \\
\text { / tons/week }\end{array}$} \\
\hline & $\begin{array}{c}\text { Tech } \\
1 \\
\end{array}$ & $\begin{array}{c}\text { Tech } \\
2 \\
\end{array}$ & $\begin{array}{c}\text { Tech } \\
3 \\
\end{array}$ & $\begin{array}{c}\text { Tech } \\
1 \\
\end{array}$ & $\begin{array}{c}\text { Tech } \\
2 \\
\end{array}$ & $\begin{array}{c}\text { Tech } \\
3 \\
\end{array}$ & $\begin{array}{c}\text { Tech } \\
1 \\
\end{array}$ & $\begin{array}{c}\text { Tech } \\
2 \\
\end{array}$ & $\begin{array}{c}\text { Tech } \\
3 \\
\end{array}$ \\
\hline 16 & 6 & 4.5 & 3 & 10 & 9 & 8 & 100 & 90 & 80 \\
\hline 17 & 6 & 4.5 & 3 & 10 & 9 & 8 & 100 & 90 & 80 \\
\hline 18 & 6 & 4.5 & 3 & 10 & 9 & 8 & 100 & 90 & 80 \\
\hline
\end{tabular}

Table 4 Recyclable percentage of used appliances after technical processing

\begin{tabular}{|c|c|c|c|}
\hline Tech. & Type1 & Type 2 & Type 3 \\
\hline Tech1 & $30 \%$ & $30 \%$ & - \\
\hline Tech2 & $50 \%$ & - & $50 \%$ \\
\hline Tech3 & - & $70 \%$ & $70 \%$ \\
\hline
\end{tabular}

Note: "- "suggests the Tech cannot dispose of this type of used appliance.

Table 5 The compatibility between the waste and vehicles

\begin{tabular}{|c|c|c|c|}
\hline Vehicle & Type1 & Type2 & Type3 \\
\hline Vehicle1 & $\mathrm{Y}$ & $\mathrm{N}$ & $\mathrm{N}$ \\
\hline Vehicle2 & $\mathrm{N}$ & $\mathrm{Y}$ & $\mathrm{N}$ \\
\hline Vehicle3 & $\mathrm{N}$ & $\mathrm{N}$ & $\mathrm{Y}$ \\
\hline
\end{tabular}

Table 6 Information of collection centers

\begin{tabular}{|c|c|c|}
\hline Candidate & $\begin{array}{c}\text { Fixed construction cost / } \\
\text { 106 yuan/year }\end{array}$ & $\begin{array}{c}\text { Maximum recollecting } \\
\text { capacity / tons/week }\end{array}$ \\
\hline 19 & 2 & 100 \\
\hline 20 & 1.8 & 85 \\
\hline 21 & 3 & 90 \\
\hline
\end{tabular}




\begin{tabular}{|c|c|c|}
\hline \multicolumn{3}{|c|}{ Table 7 Information of processing centers } \\
\begin{tabular}{|c|c|c|}
\hline Candidate & $\begin{array}{c}\text { Fixed construction cost / } \\
\text { 106 yuan/year }\end{array}$ & $\begin{array}{c}\text { Maximum processing } \\
\text { capacity / tons/week }\end{array}$ \\
\hline 19 & 2.2 & 90 \\
\hline 20 & 2.8 & 80 \\
\hline 21 & 2.8 & 85 \\
\hline
\end{tabular}
\end{tabular}

\section{(2) Computational results}

Using the above parameters, in the computer environment of Intel(R)Core(TM) i5-5200U CPU @, 2.20 $\mathrm{GHz}$ (4 CPUs), $2.2 \mathrm{GHz}$, based on designed solution steps, use Java to call Cplex 12.6 for programming calculation.

\begin{tabular}{|c|c|c|c|c|c|}
\hline Table 8 Computational data for each sub-objective \\
\hline sub-objective & Cost / yuan & $\begin{array}{c}\text { Evenly shared } \\
\text { location risk / } \\
\text { population } \\
\text { exposure tons }\end{array}$ & $\begin{array}{c}\text { Evenly shared } \\
\text { transportation } \\
\text { risk / } \\
\text { population } \\
\text { exposure tons }\end{array}$ & Time / s & GAP \\
\hline $\begin{array}{c}\text { Minimizing } \\
\text { total cost }\end{array}$ & 11885340 & 190.74 & 66.79 & 3579.1 & $0.90 \%$ \\
\hline $\begin{array}{c}\text { Minimizing } \\
\text { total location } \\
\text { risk }\end{array}$ & 25830910 & 42.41 & 81.36 & 2.39 & 0 \\
\hline $\begin{array}{c}\text { Minimizing } \\
\text { total } \\
\text { transportation } \\
\text { risk }\end{array}$ & 36417920 & 77.32 & 27.30 & 3794.66 & $12.80 \%$ \\
\hline
\end{tabular}

\begin{tabular}{|c|c|c|c|c|c|}
\hline 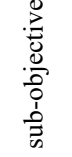 & 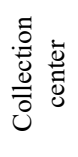 & 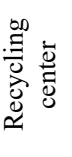 & 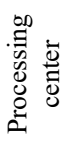 & 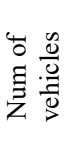 & 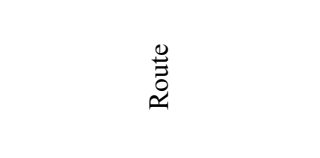 \\
\hline 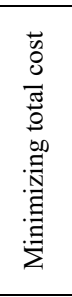 & $\begin{array}{l}16(2), \\
18(3)\end{array}$ & 20 & 22 & 6 & $\begin{array}{c}16-7-3-8-11-9-15-16(1) ; \\
18-10-6-12-4-2-1-5-14-13- \\
18(1) ; \\
16-7-3-8-6-10-9-11-14-15- \\
2-4-12-5-1-16(2) ; \\
18-13-18(2) ; \\
18-1-2-4-9-11-5-12-18(3): \\
18-10-7-14-3-8-6-15-13- \\
18(3) ;\end{array}$ \\
\hline 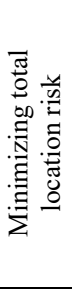 & $\begin{array}{l}16(1), \\
16(2)\end{array}$ & $\begin{array}{l}19, \\
20, \\
21\end{array}$ & $\begin{array}{l}22, \\
23 \\
24\end{array}$ & 6 & $\begin{array}{c}16-3-8-11-13-14-16(1) ; \\
16-5-10-2-15-4-7-6-12-1-9- \\
16(1) ; \\
16-8-5-12-3-2-16(2) ; \\
16-11-4-13-9-10-14-15-7-1- \\
6-16(2) ; \\
16-8-3-15-9-5-12-4-16(3) ; \\
16-10-2-7-6-1-11-14-13- \\
16(3) ;\end{array}$ \\
\hline 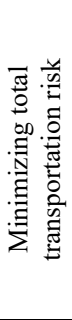 & $\begin{array}{l}16(2), \\
18(2), \\
18(3)\end{array}$ & $\begin{array}{l}19, \\
20, \\
21\end{array}$ & $\begin{array}{l}22, \\
23, \\
24\end{array}$ & 6 & $\begin{array}{c}16-3-5-8-6-4-15-16(1) ; \\
16-13-9-7-1-10-14-12-2-11- \\
16(1) ; \\
16-11-3-5-4-15-16(2) ; \\
16-13-9-7-1-10-14-2-12-8- \\
6-16(2) ; \\
16-14-12-3-15-4-11-5- \\
16(3) ; \\
18-6-8-10-9-7-1-2-13- \\
18(3) ;\end{array}$ \\
\hline
\end{tabular}

Note: the bracket number in the collection center indicates which technology is introduced, and the bracket number in the collection route indicates which type of used household appliances is transported.

First, solve the single-objective optimization problem for each sub-objective in the location-routing model. As shown in Tab. 8, the optimal value of each sub-objective can be obtained within 3795 seconds. What is more, the relative error GAP of the optimal value of the sub-target for minimizing the location risk is 0 .

$$
G A P=\frac{\mid \text { current feasible solution }- \text { lower bound } \mid}{\text { lower bound }} \times 100 \% \text {, }
$$

the smaller the GAP value of the solution, the better the solution effect. The location-routing optimization schemes for optimal solution of each sub-goal are shown in Tab. 9.

Secondly, according to the calculation results in Tab. 8 , the weighted target programming method is used to transform the multi-objective model, and the weight coefficient is selected as $\lambda_{1}=0.2, \lambda_{2}=0.3, \lambda_{3}=0.5$. The optimal solution is calculated as shown in Tab. 10 : the total cost is 13768400 yuan, the average location risk is 43.67 tonnages and the average transportation risk is 27.30 tonnages.

Table 10 The optimal location-routing scheme $\left(\lambda_{1}=0.2, \lambda_{2}=0.3, \lambda_{3}=0.5\right)$

\begin{tabular}{|c|c|c|c|c|}
\hline $\begin{array}{c}\text { Collection } \\
\text { center }\end{array}$ & $\begin{array}{c}\text { Recycling } \\
\text { center }\end{array}$ & $\begin{array}{c}\text { Processing } \\
\text { center }\end{array}$ & $\begin{array}{c}\text { Num of } \\
\text { vehicles }\end{array}$ & Route \\
\hline & & & & $16-4-9-14-10-7-3-8-$ \\
& & & & $13-16(1) ;$ \\
& & & & $16-11-12-2-5-1-6-15-$ \\
& & & & $16(1) ;$ \\
& & & & $16-7-3-8-11-13-9-10-$ \\
& & 6 & $6-16(2) ;$ \\
& & & & $16-15-14-5-12-4-2-1-$ \\
& & & & $16(2) ;$ \\
& & & & $16-5-11-12-14-13-9-$ \\
& & & & $10-6-16(3) ;$ \\
& & & & $16-15-4-1-8-3-7-$ \\
\hline
\end{tabular}

\subsection{Basic Example}

\section{(1) Weight coefficient}

In order to test the performance of the model, this article will analyze the model by adjusting the weight parameters in the same environment. The weight coefficient varies from 0 to 1 , and the span of each variation is 0.1 . A total of 66 test cases is calculated. The relevant calculation results are shown in Tab. 11 .

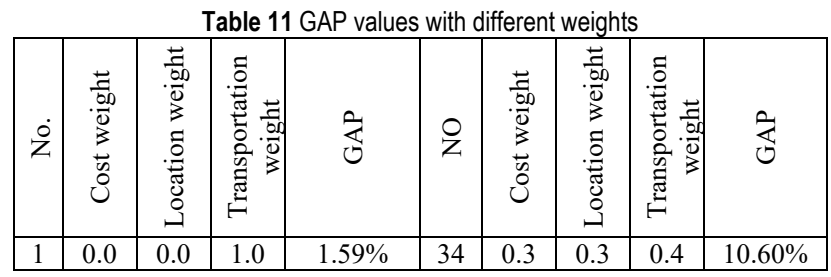

Except for the relatively large GAP values of the results $23,25,32,47,58,62$, the relative errors of the other results are all within $15 \%$, especially result 18 even gets the optimal value with an error of 0 . Therefore the model has certain validity for different weight schemes.

(2) Damage radius

Setting the damage radius to be $0.8 \mathrm{~km}$ and $8 \mathrm{~km}$, and the corresponding calculation results are compared with that of the basic calculation example. Since the total cost does not involve the radius, only the calculation results of the risk target are used for comparative analysis.

First of all, as shown in Tab. 12, when considering the optimality of sub-objective of location risk, it can be seen that the location risk and transportation risk of the calculation result with a fixed radius of $0.8 \mathrm{~km}$ are smaller than those with varied radius. But with the fixed radius of $8 \mathrm{~km}$, the risks are larger than changeable radius. This is 
because the two radia above are respectively equivalent to the minimum and maximum value in the calculation example, and this calculation method ignores the category differences among used appliances leading to a large error with actual risk.

Table 12 Radius influence with optimal sub-objective of location risk

\begin{tabular}{|c|c|c|c|}
\hline Radius & Cost / yuan & $\begin{array}{c}\text { Location risk } \\
\text { population exposure } \\
\text { tons }\end{array}$ & $\begin{array}{c}\text { Transportation risk } \\
\text { population exposure } \\
\text { tons }\end{array}$ \\
\hline $\begin{array}{c}\text { Change with } \\
\text { category }\end{array}$ & 25830910 & 1017.774 & 22456.69 \\
\hline $0.8 \mathrm{~km}$ & 25851080 & 374.2422 & 14629.19 \\
\hline $8 \mathrm{~km}$ & 25905350 & 1496.969 & 27621.63 \\
\hline
\end{tabular}

\subsection{Computational Conclusion}

First of all, the fuzzy multi-objective location and routing model and the design of solution steps constructed in this paper can provide an effective optimization scheme for basic numerical example.

Secondly, the new model and method can set the weight coefficient for each sub-objective according to the preferences of different decision makers, and then provide a variety of candidate optimization schemes for decision makers from different levels. Finally, from the point of view of risk, it is proved that damage radius will change with the variety of waste household appliances which will finally change the value of the optimization scheme.

This chapter first designs the basic solution idea according to the complexity of the fuzzy multi-objective location and routing model, and designs the concrete solution steps. Then, using the basic numerical example and sensitivity analysis of multiple parameters, the validity, sensitivity and robustness of the model and algorithm are verified. Finally, the results show that the model and method can provide several effective optimization schemes, and the optimization results are sensitive to the parameter of the damage radius.

\section{CONCLUSION}

Based on the closed loop supply chain, we design the waste household appliances recycling logistics management system. This study studies the risk management of waste household appliances recycling under uncertain conditions and constructs the risk measurement model under fuzzy population density. Considering the multi-stage of waste household appliances recycling logistics and the diversity of waste household appliances categories, the multi-objective location and routing model and location-routing model are constructed respectively. Based on the model complexity analysis, the solution method of multi-objective model is designed. Finally, the validity of the model and algorithm is verified by examples and tests.

\section{Acknowledgements}

This study is sponsored by the National Natural Science Foundation of China under Grants 51805169, 71940009, 52062015, 71662011. This study is also supported by Natural Science Foundation of Jiangxi Province under Grant 20202BABL212009.

\section{REFERENCES}

[1] Xu, W., Liu, L., Zhang, Q. et al. (2018). Location DecisionMaking of Equipment Manufacturing Enterprise under DualChannel Purchase and Sale Mode. Complexity, 2018. https://doi.org/10.1155/2018/3797131

[2] Du, J., Qiao, F., \& Yu, L. (2019). Temporal characteristics and forecasting of PM2.5 concentration based on historical data in Houston, USA. Resources Conservation and Recycling, 147, 145-156. https://doi.org/10.1016/j.resconrec.2019.04.024

[3] Du, J., Qiao, F., \& Yu, L. (2020). Improving Bus Transit Services for Disabled Individuals: Demand Clustering, Bus Assignment, and Route Optimization. IEEE Access, (99). https://doi.org/10.1109/ACCESS.2020.3007322

[4] Zografos, K. G. \& Samara, S. (1989). Combined locationrouting model for hazardous waste transportation and disposal. Transportation Research Record, 1245, 52-59.

[5] Aydemir-Karadag, A. (2018). A Profit-Oriented Mathematical Model for Hazardous Waste LocatingRouting Problem. Journal of Cleaner Production, 202(20), 213-225. https://doi.org/10.1016/j.jclepro.2018.08.106

[6] Zhao, J. \& Ke, G. Y. (2017). Incorporating inventory risks in location-routing models for explosive waste management. International Journal of Production Economics, S0925527317302086. https://doi.org/10.1016/j.ijpe.2017.07.001

[7] Rabbani, M., Heidari, R., \& Yazdanparast, R. (2018). A Stochastic Multi-Period Industrial Hazardous Waste Location-Routing Problem: Integrating NSGA-II and Monte Carlo Simulation. European Journal of Operational Research, S0377221718306295. https://doi.org/10.1016/j.ejor.2018.07.024

[8] Araee, M. \& Aghamohammadi, B. (2020). Designing a multi-objective model for a hazardous waste routing problem considering flexibility of routes and social effects. Journal of Industrial and Production Engineering, 37(1), 33-45. https://doi.org/10.1080/21681015.2020.1727970

[9] Rabbani, M., Amirhossein Sadati, S., \& Farrokhi-Asl, H. (2020). Incorporating location routing model and decision making techniques in industrial waste management: Application in the automotive industry. Computers \& Industrial Engineering, 148. https://doi.org/10.1016/j.cie.2020.106692

[10] Yilmaz, O., Kara, B. Y., \& Yetis, U. (2017). Hazardous waste management system design under population and environmental impact considerations. Journal of Environmental Management. https://doi.org/10.1016/j.jenvman.2016.06.015

[11] Asefi, H., Lim, S., Maghrebi, M. et al. (2018). Mathematical modelling and heuristic approaches to the location-routing problem of a cost-effective integrated solid waste management. Annals of Operations Research, 1-36. https://doi.org/10.1007/s10479-018-2912-1

[12] Kargar S., Paydar, M. M., \& Safaei, A. S. (2020). A reverse supply chain for medical waste: A case study in Babol healthcare sector. Waste Management, 113, 197-209. https://doi.org/10.1016/j.wasman.2020.05.052

[13] Li, H., Xu, W., Cui, Y. et al. (2019). Preventive Maintenance Decision Model of Ur-ban Transportation System Equipment Based on Multi-Control Units. IEEE Access, (99), 1-1. https://doi.org/10.1109/ACCESS.2019.2961433

[14] Deng, F., Li, Y., Lin, H. et al. (2020). A BWM-TOPSIS Hazardous Waste Inventory Safety Risk Evaluation. International Journal of Environmental Research and Public Health, 17(16). https://doi.org/10.3390/ijerph17165765

[15] Wencheng, W., Yingxin, W., Jiahui, W. et al. (2018). Regional risk assessment of trace elements in farmland soils associated with improper e-waste recycling activities in Southern China. Journal of Geochemical Exploration, 192. https://doi.org/10.1016/j.gexplo.2018.06.009 
[16] Huang, X., Wang, X., Pei, J. et al. (2018). Risk assessment of the areas along the highway due to hazardous material transportation accidents. Natural Hazards. https://doi.org/10.1007/s11069-018-3346-4

[17] Su, L., Sun, L., Karwan, M. et al. (2019). Spectral risk measure minimization in hazardous materials transportation. IIE Transactions, 51(6), 638-652. https://doi.org/10.1080/24725854.2018.1530488

[18] Kazancoglu, Y., Ozkan-Ozen, Y. D., Mangla, S. K. et al. (2020). Risk assessment for sustainability in e-waste recycling in circular economy. Clean Technologies and Environmental Policy, 2020(1) https://doi.org/10.1007/s10098-020-01901-3

[19] Ginger, Y. K., Huiwen, Z., \& Bookbinder, J. H. (2020). A dual toll policy for maintaining risk equity in hazardous materials transportation with fuzzy incident rate. International Journal of Production Economics, 227. https://doi.org/10.1016/j.ijpe.2020.107650

[20] Pirmin, F., Teodor, G. C., Michel, G. et al. (2020). Population-based risk equilibration for the multimode hazmat transport network design problem. European Journal of Operational Research, 284(1), 188-200. https://doi.org/10.1016/j.ejor.2019.12.028

[21] Zhao, J., Verma, M., \& Verter, V. (2020). Pipeline transportation of crude oil in Canada: Environmental risk assessment using modified diffusion models. Human and Ecological Risk Assessment, (2), 1-21. https://doi.org/10.1080/10807039.2020.1816808

[22] Tao, L., Chen, L., Long, P et al. (2020). Integrated Risk Assessment Method for Spent Fuel Road Transportation Accident under Complex Environment. Nuclear Engineering and Technology. https://doi.org/10.1016/j.net.2020.09.030

[23] Tirkolaee, E. B., Abbasian, P., \& Weber, G. W. (2020). Sustainable fuzzy multi-trip location-routing problem for medical waste management during the COVID-19 outbreak. Science of the Total Environment, 10, 143607. https://doi.org/10.1016/j.scitotenv.2020.143607

[24] Awaga, A. L., Xu, W., Liu, L. et al. (2020). Evolutionary game of green manufacturing mode of enterprises under the influence of government reward and punishment. Advances in Production Engineering \& Management, 15(4). https://doi.org/10.14743/apem2020.4.375

[25] Ahani, M., Arjmandi, R., Hoveidi, H. et al. (2019). A multiobjective optimization model for municipal waste management system in Tehran city, Iran. International Journal of Environmental Science and Technology. https://doi.org/10.1007/s13762-019-02335-1

[26] Rabbani, M., Heidari, R., Farrokhi-Asl, H. et al. (2018). Using metaheuristic algorithms to solve a multi-objective industrial hazardous waste location-routing problem considering incompatible waste types. Journal of Cleaner Production, S0959652617320176. https://doi.org/10.1016/j.jclepro.2017.09.029

[27] Li, H., Xu, W., Cui, Y. et al. (2019). Preventive Maintenance Decision Model of Ur-ban Transportation System Equipment Based on Multi-Control Units. IEEE Access, (99), 1-1. https://doi.org/10.1109/ACCESS.2019.2961433

[28] Wichapa, N. \& Khokhajaikiat, P. (2018). Solving a multiobjective location routing problem for infectious waste disposal using hybrid goal programming and hybrid genetic algorithm. International Journal of Industrial Engineering Computations, 9, 75-98. https://doi.org/10.5267/j.ijiec.2017.4.003

[29] Zhao, J. \& Huang, L. (2019). Multi-Period Network Design Problem in Regional Hazardous Waste Management Systems. International Journal of Environmental Research and Public Health, 16(11), 2042. https://doi.org/10.3390/ijerph16112042
[30] Homayouni, Z. \& Pishvaee, M. S. (2020). A bi-objective robust optimization model for hazardous hospital waste collection and disposal network design problem. Journal of Material Cycles and Waste Management. https://doi.org/10.1007/s10163-020-01081-8

[31] Durmaz, Y. G. \& Bilgen, B. (2020). Multi-objective optimization of sustainable biomass supply chain network design. Applied Energy, 272, 115259. https://doi.org/10.1016/j.apenergy.2020.115259

[32] Nagy, G. \& Salhi, S. (1996). Nested heuristic methods for the location-routeing problem. Journal of the Operational Research Society, 47(9), 1166-1174. https://doi.org/10.1057/jors.1996.144

[33] Nagy, G. \& Salhi, S. (1996). A nested location-routing heuristic using route length estimation. Studies in Locational Analysis, 10, 109-127.

[34] Sérgio, B., Carlos, F., José, P. et al. (2005). Using clustering analysis in a capacitated location-routing problem. European Journal of Operational Research, 179(3). https://doi.org/10.1016/j.ejor.2005.06.074

[35] Zhang, H. \& Cui, Y. (2019). A model combining a Bayesian network with a modified genetic algorithm for green supplier selection. SIMULATION: Transactions of the Society for Modeling and Simulation International, 95(12), 1165-1183. https://doi.org/10.1177/0037549719826306

[36] Jianbang, Du., Li, Q., \& Qiao, F. (2018). Estimation of vehicle emission on mainline freeway under isolated and integrated ramp metering strategies. Environmental engineering and management journal, 17(5), 1237-1248. https://doi.org/10.30638/eemj.2018.123

[37] Xu, W. \& Yin, Y. (2018). Functional objectives decisionmaking of discrete manufacturing system based on integrated ant colony optimization and particle swarm optimization approach. Advances in Production Engineering \& Management, 13(4), 389-404.

[38] Mehrdad, T., Dylan, J., \& Carlos, R. (1998). Goal programming for decision making: An overview of the current state-of-the-art. European Journal of Operational Research, 111(3). https://doi.org/10.1016/S0377-2217(97)00317-2

\section{Contact information}

\section{Luojun YANG, PhD student}

School of Transportation and Logistics,

East China Jiaotong University,

No. 808, East Shuanggang Road, Nanchang City, Jiangxi Province, China E-mail: 369565708@qq.com

Junhua GUO, Professor

(Corresponding author)

School of Transportation and Logistics,

East China Jiaotong University,

No. 808, East Shuanggang Road, Nanchang City, Jiangxi Province, China

E-mail: gjhtougao@163.com

Cheng ZHANG, Professor

School of Transportation and Logistics,

East China Jiaotong University,

No. 808, East Shuanggang Road, Nanchang City, Jiangxi Province, China

E-mail: zhangcheng001@126.com

Ping WAN, PhD

School of Transportation and Logistics,

East China Jiaotong University,

No. 808, East Shuanggang Road, Nanchang City, Jiangxi Province, China

E-mail: pingw04@163.com

Hao LI, Graduate student

School of Transportation and Logistics,

East China Jiaotong University,

No. 808, East Shuanggang Road, Nanchang City, Jiangxi Province, China

Email: 1214655435@qq.com 